\title{
Study of Interface Layer Effect in Organic Solar Cells by Electric-Field-Induced Optical Second-Harmonic Generation Measurement
}

\author{
Dai Taguchi, Ryota Sumiyoshi, Xiangyu Chen, \\ Takaaki Manaka, and Mitsumasa Iwamoto* \\ Department of Physical Electronics, Tokyo Institute of Technology, 2-12-1, \\ O-okayama, Meguro-ku, Tokyo, 152-8552 Japan
}

\begin{abstract}
By using electric-field-induced optical second-harmonic generation (EFISHG) measurement, we studied the effect of the use of bathocuproine (BCP) interface layer. The EFISHG measurements of indium-zinc-oxide (IZO)/ $\mathrm{C}_{60} / \mathrm{Al}$ diodes showed that the $\mathrm{BCP}$ layer inserted between $\mathrm{C}_{60}$ and $\mathrm{Al}$ formed an electrostatic field $\left|E_{i}\right|=$ $2.5 \times 10^{4} \mathrm{~V} / \mathrm{cm}$ in the $\mathrm{C}_{60}$ layer, pointing in a direction from the $\mathrm{Al}$ to the IZO. Accordingly, in the $\mathrm{IZO} /$ pentacene/ $\mathrm{C}_{60} / \mathrm{BCP} / \mathrm{Al}$ organic solar cells (OSCs), holes (electrons) move to the IZO (Al) electrode, enhancing the short-circuit current. The EFISHG measurement is capable of directly probing internal fields in the layers used for OSCs, and is helpful for studying the contribution of the interface layer in OSCs.
\end{abstract}

Key words: organic solar cell, internal electric field, EFISHG, Maxwell-Wagner

effect

* Corresponding author. Tel./fax:+81-3-5734-2191.

Email address: iwamoto@pe.titech.ac.jp (Mitsumasa Iwamoto).

Preprint submitted to Elsevier

24 April 2013

(C) 2013. This manuscript version is made available under the Elsevier user license http://www.elsevier.com/open-access/userlicense/1.0/ 


\section{Introduction}

Organic thin film devices have attracted much attention in electronics. Among them are organic light-emitting diodes (OLEDs) [1] and organic solar cells (OSCs) [2]. Basically, OLEDs and OSCs have the device structure with a thin

organic layer (thickness $<100 \mathrm{~nm}$ ) sandwiched between parallel two electrodes, in a manner as metal-insulator-metal (MIM) diodes. In these devices, there is a non-zero internal electric field in the film thickness direction, depending on the work-function-difference between the two electrodes. The non-zero internal electric-field assists carrier injection in OLEDs [3], whereas it assists charge separation in OSCs [4]. The introduction of very thin interface layer of bathocuproine (BCP) is known to give a significant effect on the improvement of device performance, possibly because the BCP layer is working as an exciton blocking layer $[5,6]$. However it is easy to speculate that the internal electric field distribution in OSCs will be modified by the introduction of the BCP interlayer. As such, the role of the BCP layer will not be only as an exciton blocking layer. Probing the internal electrostatic field is helpful to study the detail of the contribution of the BCP layer. We have been developing an electric-field-induced optical second-harmonic generation (EFISHG) measurement that can directly probe electric fields formed in organic devices [711]. This motivated us to study internal field formed in indium-zinc-oxide $(\mathrm{IZO}) /$ pentacene (or $\mathrm{C}_{60}$ )/ $\mathrm{Al}$ diodes with $\mathrm{BCP}$ interface layer, by using the EFISHG measurement. Results showed that the BCP layer governs the formation of the internal electrostatic field in the $\mathrm{C}_{60}$ layer, and results in the increase of short-circuit current of the $\mathrm{IZO} /$ pentacene/ $\mathrm{C}_{60} / \mathrm{BCP} / \mathrm{Al}$ OSCs. The EFISHG measurement is useful to study the contribution of interface 
layer used for OSCs.

\section{Experiment}

Figure 1a portrays the device we prepared. IZO-coated glass substrate was used as a top electrode, onto which an organic layer of $200 \mathrm{~nm}$-thick pentacene (or $\mathrm{C}_{60}$ ) layer was deposited. Subsequently, Al electrode (thickness, $100 \mathrm{~nm}$ ) was prepared by the thermal evaporation in a vacuum. A thin BCP interface layer (thickness, $5 \mathrm{~nm}$ ) was deposited on the IZO electrode or on the Al electrode. Resulting devices have the device structures of $\mathrm{IZO} / \mathrm{BCP} /$ pentacene (or $\left.\mathrm{C}_{60}\right) / \mathrm{Al}, \mathrm{IZO} /$ pentacene $\left(\right.$ or $\mathrm{C}_{60}$ )/ $\mathrm{Al}$, and IZO/pentacene $\left(\right.$ or $\mathrm{C}_{60}$ )/ $\mathrm{BCP} / \mathrm{Al}$. We also prepared the pentacene/ $\mathrm{C}_{60}$ OSCs with the structures of IZO/pentacene $(50 \mathrm{~nm}) / \mathrm{C}_{60}(50 \mathrm{~nm}) / \mathrm{Al}$ and $\mathrm{IZO} /$ pentacene $(50 \mathrm{~nm}) / \mathrm{C}_{60}(50 \mathrm{~nm}) / \mathrm{BCP}(10$ $\mathrm{nm}) / \mathrm{Al}$. These OSCs were characterized by using current-voltage (I-V) curves measured in dark and under illumination $\left(100 \mathrm{~mW} / \mathrm{cm}^{2}, \mathrm{AM} 1.5\right)$.

We carried out the EFISHG measurement to probe internal electric fields formed in the pentacene and in the $\mathrm{C}_{60}$ layers. Figure 1a illustrates the optical arrangement of the EFISHG measurement. The p-polarized laser pulse (duration $4 \mathrm{~ns}$, repetition rate $10 \mathrm{~Hz}, 1 \mathrm{~mW} / \mathrm{cm}^{2}$ ) was incident on the surface of samples at an incident angle of $45^{\circ}$, to probe electrostatic local fields $E_{0}$ formed in the film thickness direction of the layer (positive $E_{0}$ points in the direction from the IZO electrode to the $\mathrm{Al}$ electrode). In the presence of a local electric field at molecules, the second-harmonic nonlinear polarization wave $P_{2 \omega}$ (wavelength $\lambda / 2$ ) is induced due to the electromagnetic coupling between the electric-field $E_{\omega}$ of the laser beam (wavelength $\lambda$ ) and electrons in a molecule. The radiated second-harmonic light intensity is given as $[11,12]$ 


$$
I_{2 \omega} \propto\left|P_{2 \omega}\right|^{2} \propto\left|\epsilon_{0} \chi^{(3)}: E_{0} E_{\omega} E_{\omega}\right|^{2},
$$

where $\epsilon_{0}$ is the vacuum permittivity, and $\chi^{(3)}$ is the third-order nonlinear susceptibility. Eq. (1) indicates that the EFISHG intensity is proportional to the square of the local field $\left(I_{2 \omega} \propto\left|E_{0}\right|^{2}\right)$. Here $E_{0}\left(=E_{i}+E_{e}\right)$ is given as the sum of internal electrostatic fields $E_{i}$ and the external electric field $E_{e}(=V / d$, $V$ : external voltage, $d$ : distance between parallel electrodes). Therefore, an internal field is estimated as $E_{i}=-E_{e}$, by choosing the applied external voltage $V$ to be $I_{2 \omega}=0$. In the EFISHG measurement, the laser pulse was incident with a delay time $t_{d}=500 \mathrm{~ns}$ (see Fig. 1b) to measure the electric field $E_{0}$ formed in the diodes. The wavelength of the laser beam were $860 \mathrm{~nm}$ and $1000 \mathrm{~nm}$ for probing electric fields in the pentacene layer and those in the $\mathrm{C}_{60}$ layer, respectively [13-17]. Note that the 500 ns corresponds to the time needed for electrode charging.

\section{Results and Discussion}

Figure 2 shows the result of the EFISHG measurement for the pentacene diodes, where we plotted the square-root of the EFISHG intensity in proportion to the local field $\left(\sqrt{I_{2 \omega}} \propto\left|E_{0}\right|\right)$. In pentacene diodes, the EFISHG intensity reached minimum at $V_{e}=+1.5 \mathrm{~V}$, which is applied to the IZO electrode in reference to the $\mathrm{Al}$ electrode grounded. This value is in good agreement with the work-function-difference between IZO $\left(\phi_{1}=4.9 \mathrm{eV}\right)$ and $\mathrm{Al}\left(\phi_{2}=\right.$ $3.4 \mathrm{eV})$, i.e., $\Delta \phi\left(=\phi_{1}-\phi_{2}\right)=+1.5 \mathrm{~V}$, indicating that the insertion of the BCP interface layer has no relation with the value of the voltage $V_{e}$ needed to minimize the generated SHG intensity. In other words, the work-function- 
difference of electrodes governs the internal electric field formed in pentacene diodes. The internal electric field in the pentacene diode was estimated as $E_{i}\left(=-V_{e} / d\right)=-7.5 \times 10^{4} \mathrm{~V} / \mathrm{cm}$ from the EFISHG measurement. On the other hand, Fig. 3 shows the EFISHG signal generated from the $\mathrm{C}_{60}$ diodes. The voltage $V_{e}^{\prime}$ giving minimum EFISHG intensity changed as $V_{e}^{\prime}=-1 \mathrm{~V}$ for $\mathrm{IZO} / \mathrm{BCP} / \mathrm{C}_{60} / \mathrm{Al}$ diodes, $V_{e}^{\prime}=0 \mathrm{~V}$ for $\mathrm{IZO} / \mathrm{C}_{60} / \mathrm{Al}$ diodes, and $V_{e}^{\prime}=+0.5$ $\mathrm{V}$ for $\mathrm{IZO} / \mathrm{C}_{60} / \mathrm{BCP} / \mathrm{Al}$ diodes. These results showed that the $\mathrm{BCP}$ interface layer makes a significant contribution to the internal field formed in $\mathrm{C}_{60}$ diodes. In the $\mathrm{IZO} / \mathrm{BCP} / \mathrm{C}_{60} / \mathrm{Al}$ diodes, the internal field was non-zero $\left(E_{i}=\right.$ $5.0 \times 10^{4} \mathrm{~V} / \mathrm{cm}$ ) and it was pointing in the direction from the IZO electrode to the $\mathrm{Al}$ electrode. That is, charges $Q_{s}^{\prime}\left(=E_{i} d_{1}\left(C_{1}+C_{2}\right)\right)=5.6 \times 10^{-7}$ $\mathrm{C} / \mathrm{cm}^{2}$ is induced at the $\mathrm{BCP} / \mathrm{C}_{60}$ interface, due to the insertion of $\mathrm{BCP}$ interface layer $\left(d_{1}\right.$ : $\mathrm{C}_{60}$ thickness, $C_{1}=2.9 \times 10^{-8} \mathrm{C} / \mathrm{cm}^{2}: \mathrm{C}_{60}$ layer capacitance, $C_{2}=5.3 \times 10^{-7} \mathrm{C} / \mathrm{cm}^{2}:$ BCP layer capacitance). The direction of the internal field was opposite to that expected from the work-function-difference of the electrodes. In the $\mathrm{IZO} / \mathrm{C}_{60} / \mathrm{Al}$ diodes, there is no internal electric field in the $\mathrm{C}_{60}$ layer. In the $\mathrm{IZO} / \mathrm{C}_{60} / \mathrm{BCP} / \mathrm{Al}$ diodes, internal electric field was non-zero $\left(E_{i}=-2.5 \times 10^{4} \mathrm{~V} / \mathrm{cm}\right)$, and it was pointing in the direction from the Al electrode to the IZO electrode, where charges induced at the $\mathrm{C}_{60} / \mathrm{BCP}$ interface is $Q_{s}^{\prime \prime}=2.8 \times 10^{-7} \mathrm{C} / \mathrm{cm}^{2}$.

Figure 4 shows the I-V characteristics of the pentacene/ $\mathrm{C}_{60}$ OSCs with and without the BCP interface layer. The OSC without the BCP interface layer was characterized as that the open-circuit voltage $V_{o c}=0.08 \mathrm{~V}$, short-circuit current $J_{s c}=0.6 \mathrm{~mA} / \mathrm{cm}^{2}$, and fill-factor $F F=0.22$. Meanwhile, the OSC with the BCP interface layer was significantly improved as that $V_{o c}=0.3 \mathrm{~V}$, $J_{s c}=3.7 \mathrm{~mA} / \mathrm{cm}^{2}$, and $\mathrm{FF}=0.35$. In pentacene $/ \mathrm{C}_{60}$ OSCs, holes (electrons) 
are created at the pentacene $/ \mathrm{C}_{60}$ interface under illumination, then they move through pentacene $\left(\mathrm{C}_{60}\right)$, and transfer to the IZO $(\mathrm{Al})$ electrode. Accordingly, a short-circuit current flowed in the OSCs in the direction from the Al electrode to the IZO electrode. The internal electrostatic field pointing from the Al to the IZO smoothly conveys the holes and electrons toward the electrodes. As shown by the EFISHG results, inserting a BCP layer between the $\mathrm{C}_{60}$ layer and the $\mathrm{Al}$ electrode is one of the best ways to optimize the internal electric field to enhance the short-circuit current. These results verified that the BCP interface layer governed the internal electrostatic field formed in the OSCs, and enhanced the short-circuit current.

We here discuss the effect of the use of $\mathrm{BCP}$ layer in pentacene and $\mathrm{C}_{60}$ diodes, based on the Maxwell-Wagner effect model $[18,19]$. According to the Maxwell's electromagnetic theory, excess charge $Q_{s}$ accumulates at the interface between two dielectric materials with different relaxation time given by $\tau\left(=\epsilon / \sigma, \epsilon\right.$ : dielectric constant, $\sigma$ : conductivity), when current $I_{c}$ flows across the two-material interface. The accumulated charge density $Q_{s}$ is given by the product of the current and the difference of the relaxation times as $Q_{s}=I_{c}\left(\tau_{2}-\tau_{1}\right)$. This is the Maxwell-Wagner (MW) effect [20], indicating that $Q_{s}(\neq 0)$ accumulates at the interface when two adjacent materials have different relaxation times $\left(\tau_{1} \neq \tau_{2}\right)$. The MW effect points out a possibility that charges accumulate at the interface between $\mathrm{C}_{60}$ (or pentacene) $\left(\tau_{1}\right)$ and $\operatorname{BCP}\left(\tau_{2}\right)$. In the limit $\tau_{2} \rightarrow \infty$, electrical current is zero, $I_{c}=0$, but charges accumulate due to the MW effect, $\left(I_{c} \cdot \tau_{2} \neq 0\right)[18]$. In the $\mathrm{IZO} / \mathrm{BCP} / \mathrm{C}_{60} / \mathrm{Al}$ diodes, internal electric field is pointing in the direction from the IZO to the $\mathrm{Al}$, as shown by the EFISHG results. In the diodes, electrons transfer from the $\mathrm{BCP}$ to the $\mathrm{C}_{60}$ layer, and smoothly move across the $\mathrm{C}_{60}$ layer. As a re- 
sult, positive excess charges remain at the $\mathrm{BCP} / \mathrm{C}_{60}$ interface due to the $\mathrm{MW}$ effect. The positive excess charges form an electrostatic field pointing in the direction from the $\mathrm{BCP} / \mathrm{C}_{60}$ interface to the $\mathrm{Al}$ electrode, showing good agreement to the EFISHG results. In the $\mathrm{IZO} / \mathrm{C}_{60} / \mathrm{BCP} / \mathrm{Al}$ diodes, the EFISHG measurement showed that the internal field is pointing in the direction from the Al to the IZO. The MW effect suggests that the electrons transfer from the $\mathrm{BCP}$ to the $\mathrm{C}_{60}$, and positive charges remained at the $\mathrm{C}_{60} / \mathrm{BCP}$ interface. As a result, the remained positive charges formed internal field pointing in the direction from the $\mathrm{C}_{60} / \mathrm{BCP}$ interface to the IZO electrode, which again showed good agreement with the EFISHG results. On the other hand, in the pentacene diodes, electrons could transfer from the $\mathrm{BCP}$ to the pentacene, but the pentacene acts mainly as an electron insulating layer $\left(\tau_{2} \sim \tau_{1}\right)$. As the result, the $\mathrm{BCP}$ layer in the pentacene diodes never contribute to the excess charge accumulation, $Q_{s}\left(=I_{c}\left(\tau_{2}-\tau_{1}\right)\right)=0$, and gave no effect on the internal electric field in the diodes. The MW effect well accounts for the contribution of the BCP interface layer to the internal electric field, and is helpful to discuss the interface layer effect.

\section{Conclusion}

By using the electric-field-induced optical second-harmonic generation (EFISHG) measurement, we directly probed internal electrostatic fields formed in the pentacene and the $\mathrm{C}_{60}$ layer, on focusing the role of bathocuproine (BCP) interface layer. Introduction of a $\mathrm{BCP}$ layer between $\mathrm{C}_{60}$ and $\mathrm{Al}$ formed an internal electrostatic field that points in the direction from the Al electrode to the IZO electrode. As a result, holes and electrons were conveyed to 
the IZO and $\mathrm{Al}$ electrodes, respectively, and the short-circuit current of the $\mathrm{IZO} /$ pentacene $/ \mathrm{C}_{60} / \mathrm{BCP} / \mathrm{Al}$ OSCs was enhanced accordingly. The EFISHG measurement can directly probe internal fields in organic layers used for OSCs, and is helpful for studying the contribution of the interface layer.

\section{Acknowledgements}

A part of this work was financially supported by a Grant-in-Aid for Scientific Research (S) (No. 22226007) from Japanese Society for the Promotion of Science, and the development of the EFISHG measurement system was supported by SENTAN from JST.

\section{References}

[1] T. Tsujimura, OLED Display Fundamentals and Applications, Wiley, Weinheim, 2012.

[2] C. Brabec, U. Scherf, V. Dyakonov, Organic Photovoltaics, Wiley-VCH, Weinheim, 2008.

[3] M. C. Gather, R. Jin, J. de Mello, D. D. C. Bradley, K. Meerholz, Appl. Phys. B 95 (2009) 113.

[4] I. Hiromitsu, S. Mada, A. Inoue, Y. Yoshida, S. Tanaka, Jpn. J. Appl. Phys. 46 (2007) 7241.

[5] P. Peumans, V. Bulović, S. R. Forrest, Appl. Phys. Lett. 76 (2000) 2650.

[6] S. Yoo, B. Domercq, B. Kippelen, Appl. Phys. Lett. 85 (2004) 5427. 
[7] D. Taguchi, T. Shino, L. Zhang, J. Li, M. Weis, T. Manaka, M. Iwamoto, Appl. Phys. Express 4 (2011) 021602.

[8] D. Taguchi, T. Shino, X. Chen, L. Zhang, J. Li, M. Weis, T. Manaka, M. Iwamoto, Appl. Phys. Lett. 98 (2011) 133507.

[9] D. Taguchi, T. Shino, X. Chen, L. Zhang, J. Li, M. Weis, T. Manaka, M. Iwamoto, J. Appl. Phys. 110 (2011) 103717.

[10] D. Taguchi, M. Weis, T. Manaka, M. Iwamoto, Appl. Phys. Lett. 95 (2009) 263310.

[11] M. Iwamoto, T. Manaka, M. Weis, D. Taguchi, J. Vac. Sci. Technol. B 28 (2010) C5F12.

[12] T. Verbiest, K. Clays, V. Rodriguez, Second-Order Nonlinear Optical Characterization Techniques, CRC, New York, 2009.

[13] L. Zhang, D. Taguchi, J. Li, T. Manaka, M. Iwamoto, J. Appl. Phys. 108 (2010) 093707.

[14] L. Zhang, D. Taguchi, J. Li, T. Manaka, M. Iwamoto, Appl. Phys. Lett. 98 (2011) 092109.

[15] X. Chen, D. Taguchi, K. Lee, T. Manaka, M. Iwamoto, Jpn. J. Appl. Phys. 51 (2012) 02BK01.

[16] X. Chen, D. Taguchi, T. Manaka, M. Iwamoto, J. Appl. Phys. 111 (2012) 113711.

[17] X. Chen, D. Taguchi, M. Weis, T. Manaka, M. Iwamoto, Jpn. J. Appl. Phys. 51 (2012) 041605.

[18] R. Tamura, E. Lim, T. Manaka, M. Iwamoto, J. Appl. Phys. 100 (2000) 114515.

[19] E. Lim, T. Manaka, M. Iwamoto, J. Appl. Phys. 104 (2008) 054511. 
[20] J. C. Maxwell, A Treatise on Electricity \& Magnetism, 3rd ed., Dover, New York, 1954, Vol. 1, Chap. X, pp 450-464. 


\section{Figure captions}

Figure 1: (a) Experimental arrangements for the EFISHG measurement. (b) Timing chart of the square-wave voltage and laser pulse incidence.

Figure 2: (a) Pentacene diodes with and without BCP interlayer. (b) The square-root of SH light intensity from the pentacene diodes under voltage application.

Figure 3: (a) $\mathrm{C}_{60}$ diodes with and without BCP interlayer. (b) The squareroot of $\mathrm{SH}$ light intensity from the $\mathrm{C}_{60}$ diodes.

Figure 4: (a) Pentacene/ $\mathrm{C}_{60}$ OSCs with and without BCP interface layer. (b) I-V characteristics of the OSCs in dark and under illumination. 
Figure 1

a.

b.

laser beam wavelength $\lambda$ optical

\section{SHG}

$\lambda / 2$

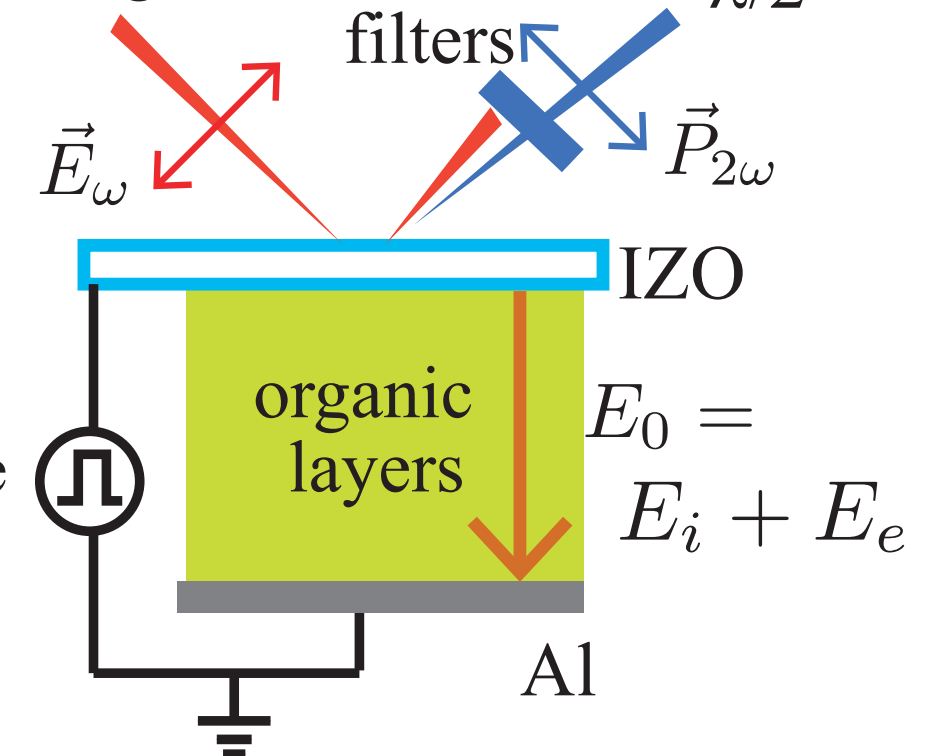

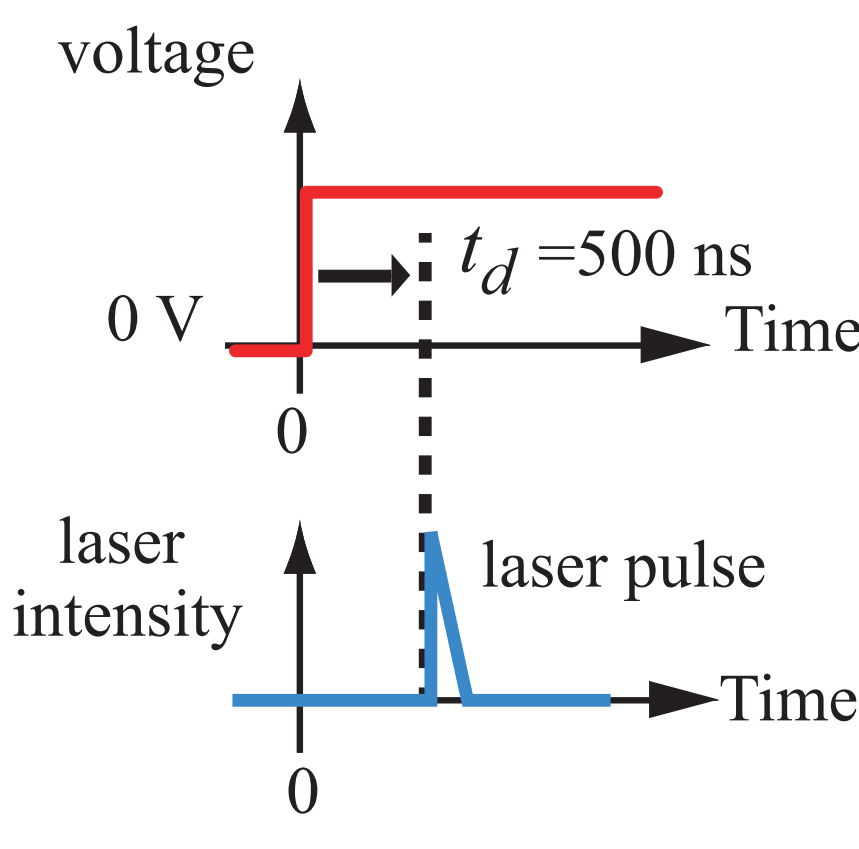


a.

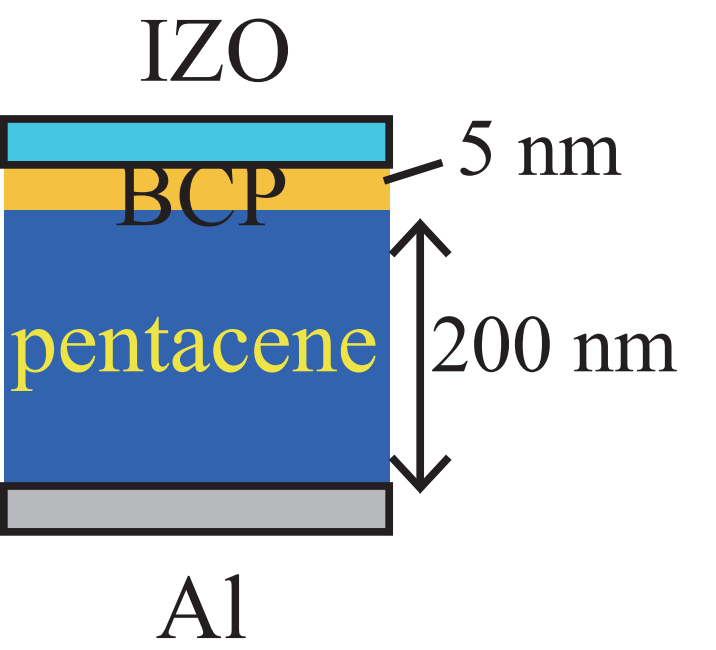

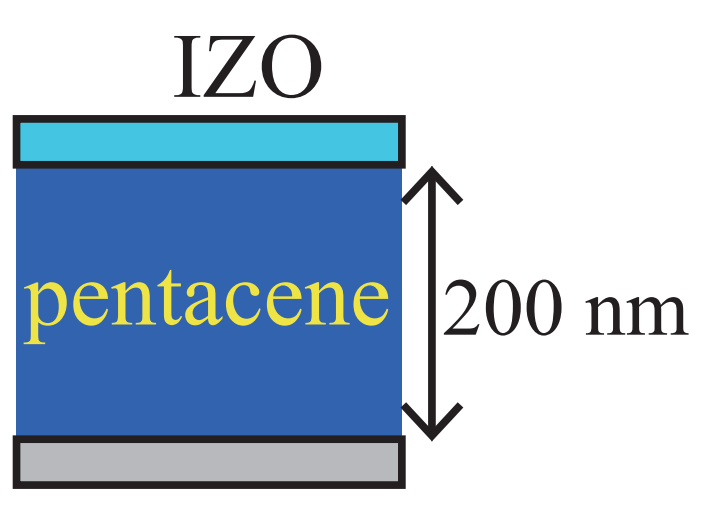

Al
IZO

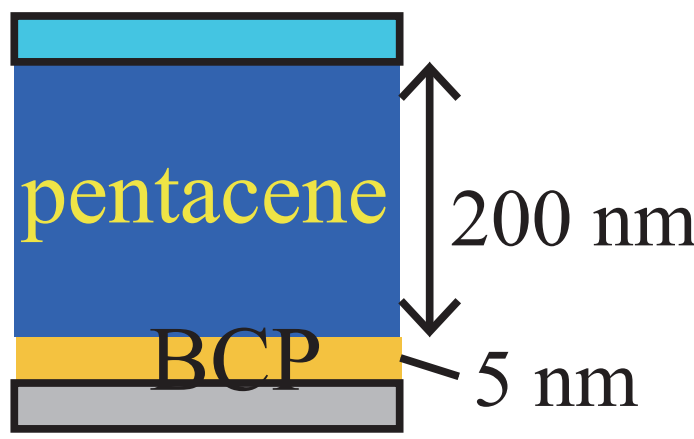

Al

b.

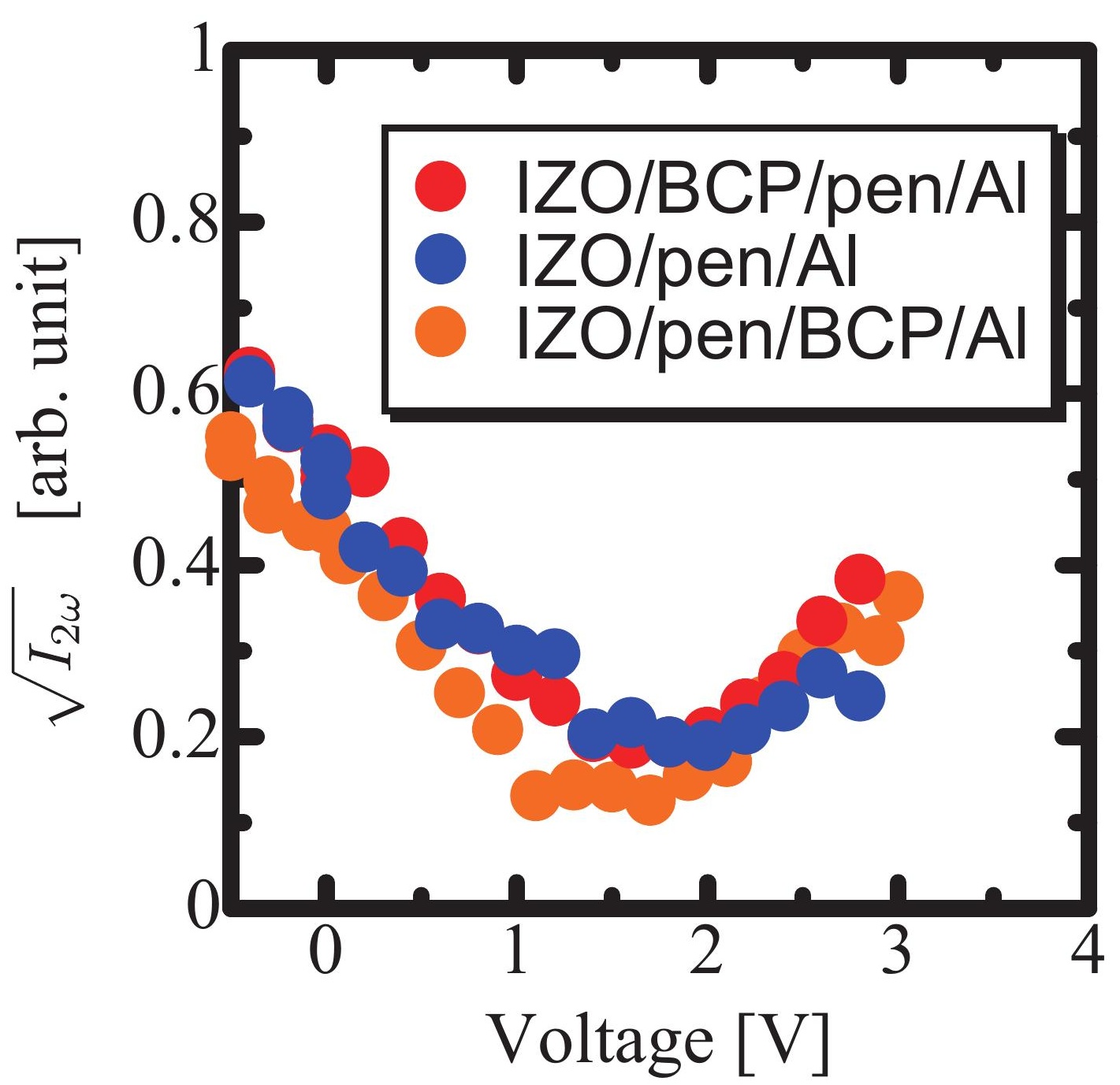


a.

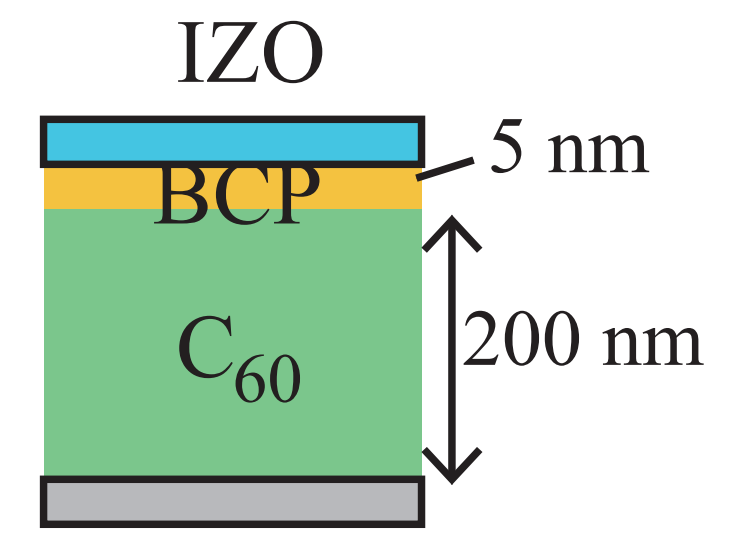

$\mathrm{Al}$

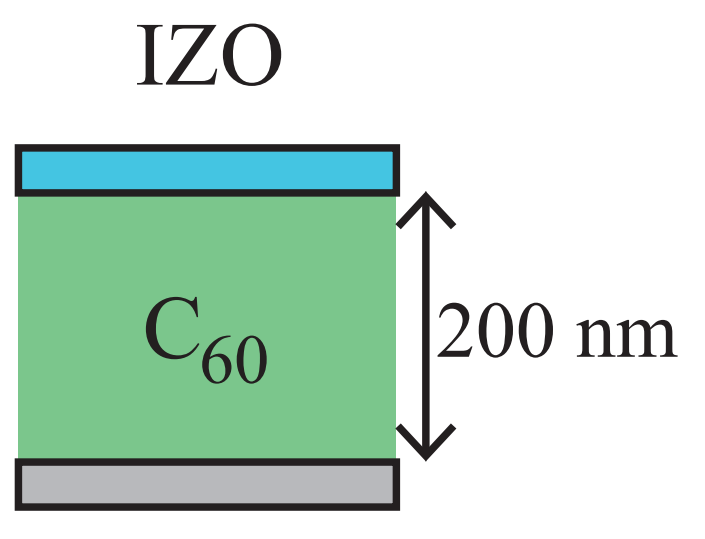

$\mathrm{Al}$

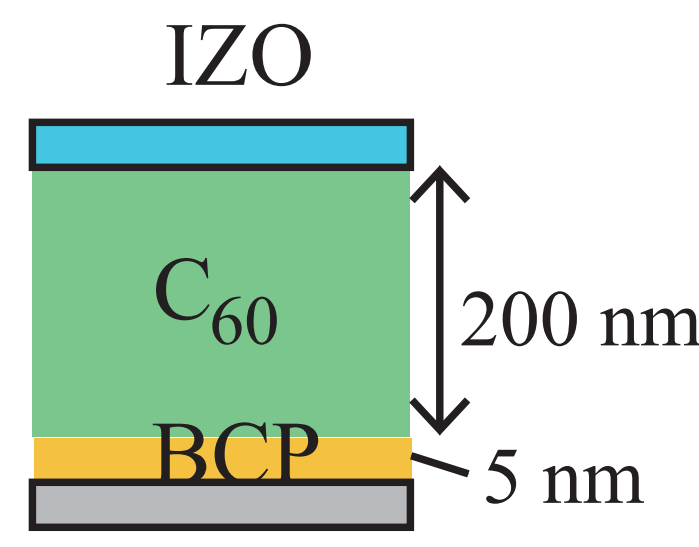

Al

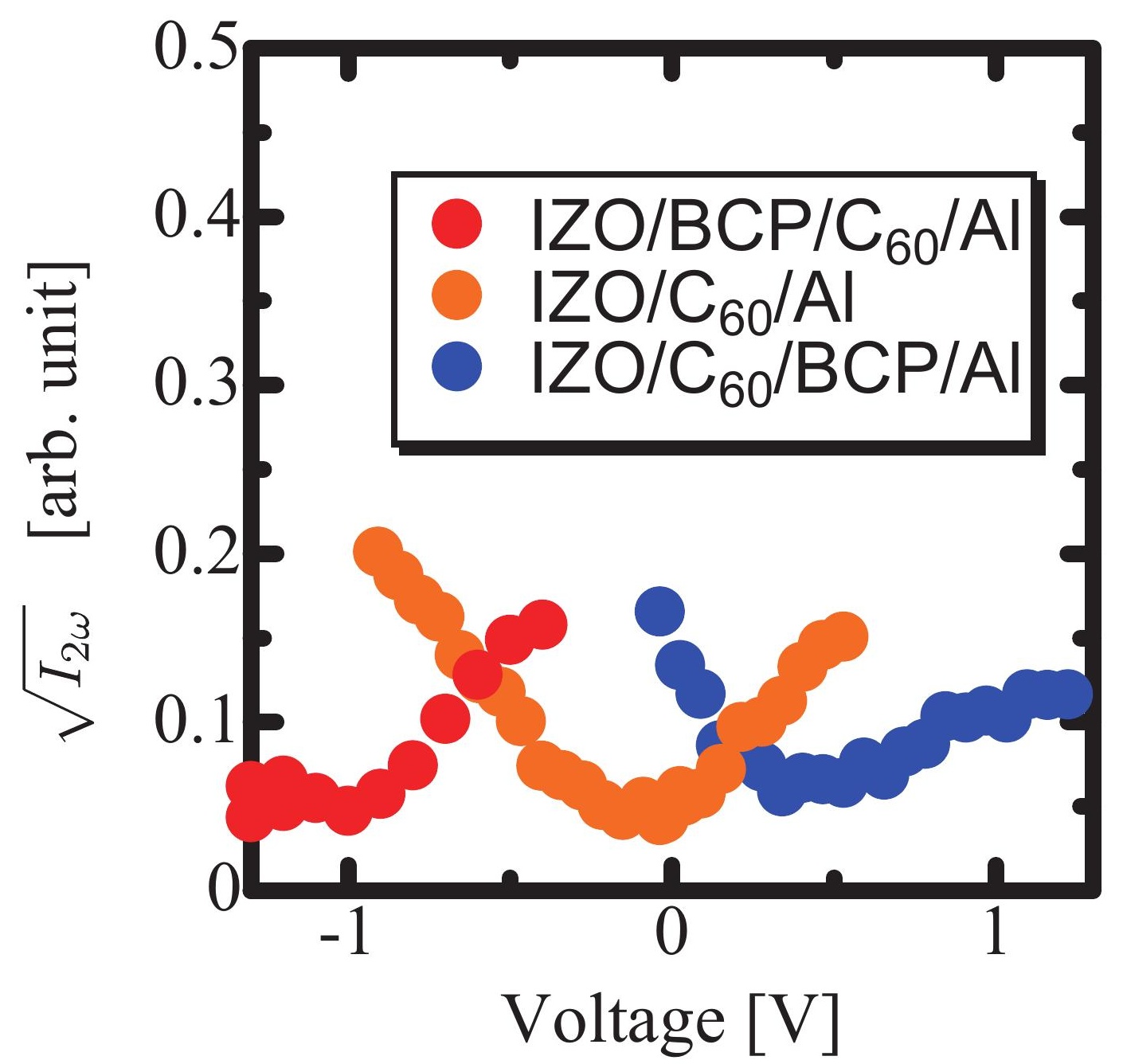

b.

IZO/BCP/C $60 / A I$ $2 \mathrm{O} / \mathrm{C}_{60} / \mathrm{Al}$ $\mathrm{ZO} / \mathrm{C}_{60} / \mathrm{BCP} / \mathrm{Al}$ 
Ejgure 4

a.
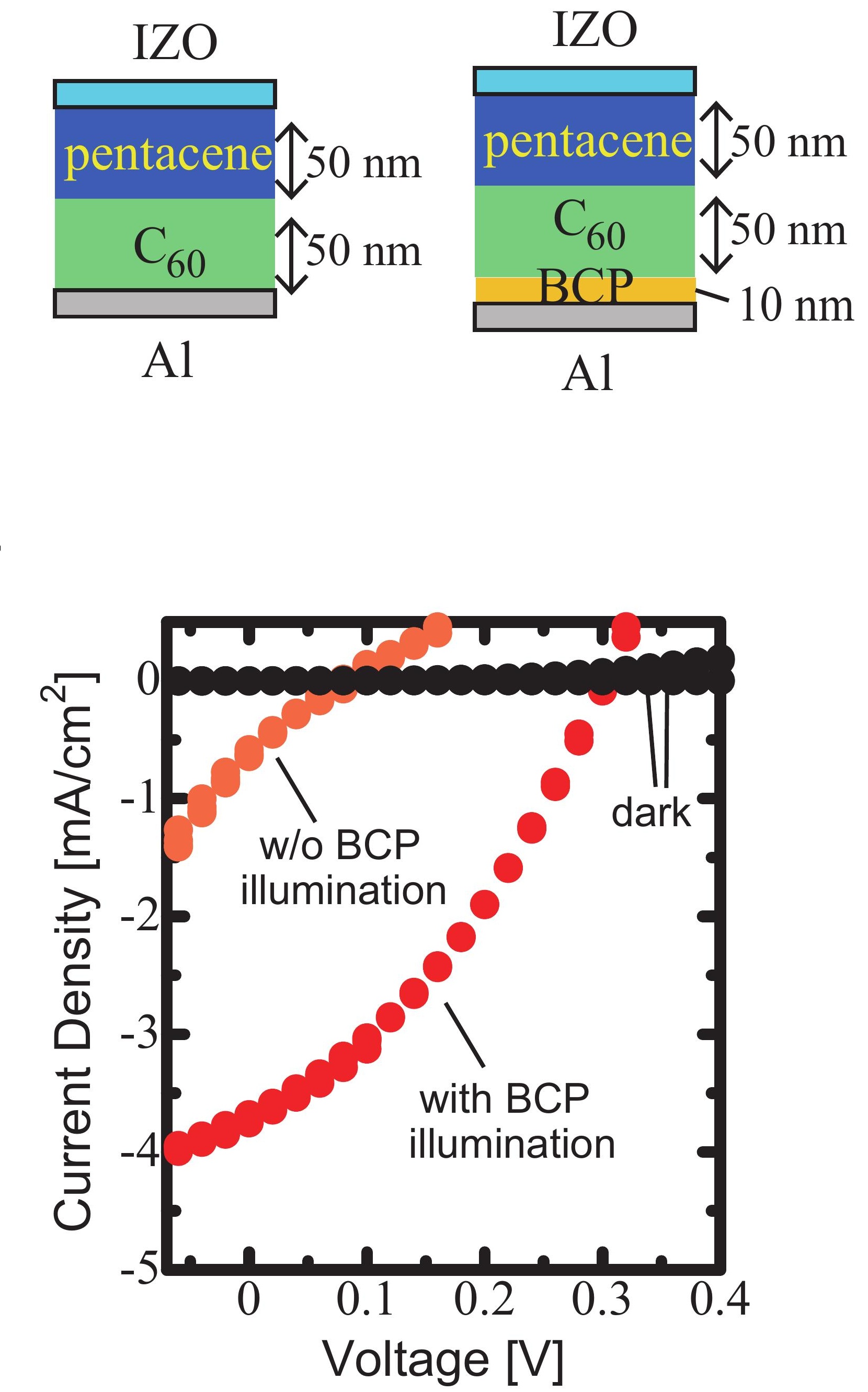

b.

Al 